\title{
ACCOMMODATING ENERGY PRICE VOLATILITY IN LIFE CYCLE COST ANALYSIS OF ASPHALT PAVEMENTS
}

\author{
Iman MIRZADEH ${ }^{\mathrm{a}}$, Bjorn BIRGISSON ${ }^{\mathrm{b}}$ \\ ${ }^{a}$ Swedish National Road and Transport Research Institute, Infrastructure, Infrastructure Maintenance, \\ Box 55685, 10215 Stockholm, Sweden \\ ${ }^{b}$ School of Engineering and Applied Science, Aston University, Aston Triangle, Birmingham B4 7ET, UK
}

Received 13 Nov 2013; accepted 22 May 2014

\begin{abstract}
Energy price is related to more than half of the total life cycle cost of asphalt pavements. Furthermore, the fluctuation related to price of energy has been much higher than the general inflation and interest rate. This makes the energy price inflation an important variable that should be addressed when performing life cycle cost (LCC) studies regarding asphalt pavements. The present value of future costs is highly sensitive to the selected discount rate. Therefore, the choice of the discount rate is the most critical element in LCC analysis during the life time of a project. The objective of the paper is to present a discount rate for asphalt pavement projects as a function of interest rate, general inflation and energy price inflation. The discount rate is defined based on the portion of the energy related costs during the life time of the pavement. Consequently, it can reflect the financial risks related to the energy price in asphalt pavement projects. It is suggested that a discount rate sensitivity analysis for asphalt pavements in Sweden should range between -20 and $30 \%$.
\end{abstract}

Keywords: road \& highways, life cycle cost, pavement design, discount rate.

\section{Introduction}

The price of energy has been identified as one of the most important factors affecting the cost of construction projects (Hastak, Shaked 2000; Baloi, Price 2003; Jaafari 2001). Furthermore, the increase in cost of oil products has been the main cause of rise in highway construction cost (Wilmot, Cheng 2003). In the mid-2000 highway construction showed a sharp increase in prices (Zhou, Damnjanovic 2011). Consequently, construction projects in 2006 were valued two times more than similar projects in 1997 (Pandit et al. 2009). This was believed to be related to the dramatic increase in the price of crude oil and its products such as bitumen, fuel oil and transportation fuel. Evidently, a direct correlation between the oil price and the cost of asphalt pavement projects exists (Gallagher, Riggs 2006; Damnjanovic, Zhou 2009). In a recent study conducted by the authors the crude oil price was closely related to more than $50 \%$ of the cost of asphalt pavement during its life time (Mirzadeh et al. 2013). Different approaches such as real option models (e.g. Garvin, Cheah 2004; Zhao et al. 2004; Chiara et al. 2007; Brandao, Saraiva 2008; Cui et al. 2004; Vassallo 2006), the neural network modelling (e.g. Sonmez, Ontepeli 2009; Baalousha, Çelik 2011; Wilmot, Mei 2005; Hegazy, Ayed 1998; Sodikov 2005) and discounted cash flow (DCF) are used for cost evaluation of infrastructure projects. Due to its simplicity, DCF analysis which provides net present value (NPV) of a project is the most common approach among the practitioners (Yeo, Qiu 2003). Moreover, it has been used by the Swedish transport administration for evaluating the infrastructure projects. The present value of future costs and benefits are highly sensitive to discount rate. Therefore, the choice of the discount rate is the most critical element in any evaluation of costs and benefits during the life time of a project. Often, decision makers are faced with the problem of either investing more initially or saving money for maintenance and rehabilitation. The extent to which discounted future costs exceed the initial costs depends directly on the discount rate. The social discount rate is used for public infrastructure projects. Different approaches such as social rate of time preferences (SRTP), marginal social opportunity cost of capital (SOC), weight average (WA) and shadow price of capital (SPC) have been applied for selecting the social discount rate. Evans and Sezer (2005) estimated discount rates, based on the social rate of time preferences, for countries such as USA, UK, Germany, Japan, France and Australia. Their results ranged between 3-5\% which clearly contradicted with the official discount rate at the time. Azar (2007) suggested that the social discount rate for the US is $5.66 \%$, with a $95 \%$ confidence interval ranging from 5.62 to $5.71 \%$. However, Lally (2008)

Corresponding author: Iman Mirzadeh

E-mail:iman.mirzadeh@abe.kth.se 
argued that this underestimates the confidence interval on the discount rate primarily through ignoring uncertainty surrounding the expected return on risky assets. Percoco (2008) suggested a discount rate for Italy which was 1.2 to $1.3 \%$ lower than the official discount rate $(5 \%)$. Due to the lack of an agreed approach for selecting the discount rate for the evaluation of the public projects, many transport agencies across and within countries have used different discount rates for their public projects (e.g. Ferreira, Santos 2013). Moreover, the social discount rate reflects the general inflation in each country. However, due to high amount of energy related costs in asphalt pavement projects, the inflation regarding this sector is usually different from the rest of economy. Therefore, the use of social discount rate for asphalt pavements can be questioned. The other common method which calculates the discount rate for a specific project is capital asset pricing model (CAPM). The CAPM is widely used in calculating the discount rate regarding public private partnership (PPP) or built operate transfer (BOT) projects (e.g. Yeo, Qiu 2003; Lee et al. 2009; Fama, French 2004; Campbell 1993). The CAPM is based on the modern portfolio theory developed by Markowitz (1952). In the CAPM model the expected return is presented in terms of the risk free rate, e.g. interest rate arising from government bonds, plus a risk premium. Therefore, the calculation of the discount rate is a qualitative assessment of how much to increase the discount rate over the risk free rate to account for the projects' risk (Baker, Fox 2003). As a result, a higher risk gives a higher discount rate. Consequently, the NPV decreases due to a higher discount rate. A lower NPV regarding revenues due to a higher risk is reasonable. However, a lower NPV regarding cost due to higher risk is not relevant. In order to deal with this problem, the authors used an approach based on the modern portfolio theory to calculate the discount rate. In modern portfolio theory the return on a portfolio is the proportion-weighted combination of the constituent assets' returns (e.g. Sharpe 1964; Elton et al. 2007; Melicher, Norton 2010). It was shown that more than $50 \%$ of the total LCC of asphalt pavement is related to oil products (Mirzadeh et al. 2013). Additionally, the fluctuation related to oil price has been more than the general inflation and interest rate (Fig. 1). Consequently, calculation of the discount rate cannot be

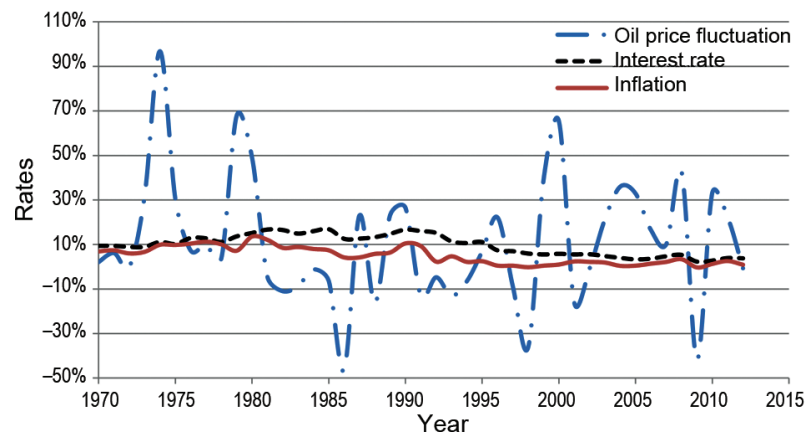

Fig. 1. The yearly average crude inflation, lending interest rate (World Bank 2012) and inflation for Sweden done based on a homogeneous inflation. However, based on the modern portfolio theory an equivalent discount rate for asphalt pavement projects can be defined as the sum of two separate discount rates.

The objective of the paper is to present a discount rate for asphalt pavement costs as a function of interest rate, general inflation and oil price inflation. The discount rate is defined based on the portion of the energy related costs during the life time of the pavement. It reflects the financial risks related to the costs asphalt pavement projects. Furthermore, it can be applied for costs calculation regarding both public and PPP projects.

\section{Methodology}

In traditional LCC of asphalt pavements the calculation of the discount rate has generally been based on the interest rate and inflation. However, the fluctuation regarding the energy price has been more than the general inflation. The price of oil products was shown to be related to more than half of the costs related to asphalt pavement life cycle. In order to capture the financial risk related to cost of oil products, the cost items were divided into energy and time related items. Energy related items are those affected by the crude oil price such as bitumen, modifier, fuel oil and transportation fuel (Table 1). The price of bitumen and modifiers is calculated as the sum of the costs related to crude oil and production in the refinery. The amount of energy for the transportation was related to the required material distribution from the refinery to the construction site. The agency-related expended energy was attributed to laying, compacting, milling and resurfacing. Furthermore, the user-related expended energy was defined for the extra amount of fuel used by the vehicles in the work zone. The unit cost of energy for each activity can be calculated via Eqn (1). Time related costs are defined as those affected by the general inflation such as labor and equipment costs (Table 2) (Eqn (2)). The value of time

Table 1. Energy related variables

\begin{tabular}{|c|c|c|c|c|}
\hline & $\begin{array}{l}\text { Crude } \\
\text { oil } \\
(\mathrm{MJ})\end{array}$ & $\begin{array}{c}\text { Energy } \\
\text { source A } \\
(\mathrm{MJ})\end{array}$ & $\begin{array}{c}\text { Energy } \\
\text { source } \\
\text { B }(\mathrm{MJ})\end{array}$ & $\begin{array}{l}\text { Cost of } \\
\text { Energy } \\
\quad(€)\end{array}$ \\
\hline Bitumen & $q c_{1}$ & - & - & $C E_{1}$ \\
\hline Modifier & $q c_{2}$ & - & - & $C E_{2}$ \\
\hline Aggregate production & - & $q a_{3}$ & $q b_{3}$ & $C E_{3}$ \\
\hline Bitumen production & - & $q a_{4}$ & $q b_{4}$ & $C E_{4}$ \\
\hline Modifier production & - & $q a_{5}$ & $q b_{5}$ & $C E_{5}$ \\
\hline Asphalt production & - & $q a_{6}$ & $q b_{6}$ & $C E_{6}$ \\
\hline Transportation & - & $q a_{7}$ & $q b_{7}$ & $C E_{7}$ \\
\hline Laying asphalt & - & $q a_{8}$ & $q b_{8}$ & $C E_{8}$ \\
\hline Compacting asphalt & - & $q a_{9}$ & $q b_{9}$ & $C E_{9}$ \\
\hline User's energy loss & - & $q a_{10}$ & $q b_{10}$ & $C E_{10}$ \\
\hline
\end{tabular}


Table 2 . Time related variables

\begin{tabular}{l|lccc}
\hline \multicolumn{1}{c}{ Item } & $\begin{array}{c}\text { Time } \\
\text { Spent } \\
(\mathrm{Hr} .)\end{array}$ & $\begin{array}{c}\text { Value } \\
\text { of time } \\
(€ / \mathrm{Hr})\end{array}$ & $\begin{array}{c}\text { Cost } \\
\text { of time } \\
(€)\end{array}$ \\
\hline \multirow{4}{*}{$\begin{array}{l}\text { Labor \& } \\
\text { equipment }\end{array}$} & Transportation & $t_{1}$ & $V_{1}$ & $C T_{1}$ \\
\cline { 2 - 5 } & Laying asphalt & $t_{2}$ & $V_{2}$ & $C T_{2}$ \\
\cline { 2 - 5 } & Compacting asphalt & $t_{3}$ & $V_{3}$ & $C T_{3}$ \\
\cline { 2 - 6 } & $\begin{array}{l}\text { Milling and } \\
\text { resurfacing }\end{array}$ & $t_{4}$ & $V_{4}$ & $C T_{4}$ \\
\hline Road users & User's delay cost & $t_{5}$ & $V_{u}$ & $C T_{5}$ \\
\hline
\end{tabular}

included the hourly wage of the labors together with the amount of hourly depreciation regarding the equipment. The hourly depreciation was defined as the initial price of the equipment divided by the useful life of the equipment (hours). The calculation regarding the user delay cost has to be done separately for the personal cars and heavy vehicles, since they should be treated with different values of time. The road user costs are defined as those related to energy loss and delay for the road users during maintenance and rehabilitation activities. The amount of energy spent (MJ/tonne), time spent $(\mathrm{hr} / \mathrm{km})$, unit price of energy $(€ / \mathrm{MJ})$ and unit value of time $(€ / \mathrm{hr})$ for different Swedish mixes are presented by Mirzadeh et al. (2013).

$$
C E=\sum_{k=1}^{n}\left(q c_{k} \times P_{c}+q a_{k} \times P_{a}+q b_{k} \times P_{b}+\ldots\right),
$$

where: $C E$ is the unit cost of energy related items for a construction/rehabilitation activity; $q c_{k}, q a_{k}$ and $q b_{k}$ are the quantities (MJ) regarding crude oil, energy source A and $\mathrm{B} ; P_{c}, P_{a}$ and $P_{b}$ are the unit prices $(€ / \mathrm{MJ})$ regarding crude oil, energy source A and B at the base year;

$$
C T=\sum_{k=1}^{n} V_{k} \times t_{k}
$$

where: $C T$ is the unit cost of time related items for a construction/rehabilitation activity; $t_{k}$ is the amount of time spent for each item; $V_{k}$ is the value of time for each item.

The most common method used to compare past and future cash flow with those of today is NPV method. Costs regarding initial construction, maintenance and rehabilitation occur at different times. Therefore, it is essential to use a discount rate in order to reflect the time value of money. The time value of money results from inflation and opportunity cost. Inflation is the rise in the general level of prices of goods and services in an economy over a period of time. Opportunity cost is equivalent to the benefit, the cash could have achieved, had it been spent differently or invested. The $N P V$ for a construction/rehabilitation cost $(C)$ at the $\mathrm{y}^{\text {th }}$ year can be calculated form Eqn (3) based on the discount rate (FHWA 2002):

$$
N P V=C \times\left(\frac{1}{1+r}\right)^{y} .
$$

The traditional discount rate $(r)$ is calculated according to Churchill and Panesar (2013):

$$
r=\frac{1+i}{1+j}-1,
$$

where: $i$ and $j$ are the rate of interest and inflation. Since $C$ consists of energy related costs $(C E)$ and time related costs $(C T)$, the discount rate should reflect inflations both regarding $C E$ and $C T$. The inflation regarding $C E$ and $C T$ are defined as crude inflation and general inflation respectively.

For a portfolio consisting of investments $a$ and $b$ where portion $\alpha$ of the wealth is placed in a and $(1-\alpha)$ in $b$ the equivalent rate of return and its standard deviation are expressed in Eqns (5)-(6) (Strong 2008):

$$
\begin{gathered}
r=\alpha \cdot r_{a}+(1-\alpha) \cdot r_{b} ; \\
\sigma=\sqrt{\alpha^{2} \sigma_{a}^{2}+(1-\alpha)^{2} \sigma_{b}^{2}+2 \beta \alpha(1-\alpha) \sigma_{a} \sigma_{b}},
\end{gathered}
$$

where: $r_{a}$ and $r_{b}$ are the return on investments and $\sigma_{a}, \sigma_{b}$ are their standard deviations. $\beta$ is the correlation coefficient between the rates of return of the two investments. A positive value for $\beta$ indicates that there is a positive correlation between $r_{a}$ and $r_{b}$. A zero value would indicate that $r_{a}$ and $r_{b}$ are completely independent. Furthermore, a negative value indicates that there is an inverse relationship between them.

It was shown by Mirzadeh et al. (2013) that crude oil inflation can be used as the inflation index for the energy related items. Consequently, the crude oil discount rate $\left(r_{1}\right)$ can be used as the discount rate for the energy related costs. The traditional discount rate is the discount rate for the time related items $\left(r_{0}\right)$. Assuming $\alpha$ as the portion of the energy related costs Eqns (5)-(6) can be rewritten as:

$$
\begin{gathered}
r=\alpha \cdot r_{1}+(1-\alpha) \cdot r_{0} ; \\
\sigma=\sqrt{\alpha^{2} \sigma_{1}^{2}+(1-\alpha)^{2} \sigma_{0}^{2}+2 \beta \alpha(1-\alpha) \sigma_{1} \sigma_{0}},
\end{gathered}
$$

where: $r$ is defined as the equivalent discount rate. $r_{1}$ is the discount rate for energy related items based on the interest rate and the crude oil inflation. Moreover, $\sigma_{1}$ is its standard deviation. $r_{0}$ is the traditional discount rate based on interest rate and general inflation and $\sigma_{0}$ is its corresponding standard deviation. The portion of energy related costs $(\alpha)$ can vary between zero to one. In this context $\beta$ is chosen to describe the correlated volatility of $r_{1}$ in relation to $r_{0}$ (Eqn (9)):

$$
\beta=\frac{\operatorname{Cov}\left(r_{1}, r_{0}\right)}{\operatorname{Var}\left(r_{0}\right)} .
$$

By inserting the interest rate, the general inflation and the crude oil inflation Eqn (7) can be rewritten as:

$$
r=\alpha \times(1+i) \times\left(\frac{1}{1+j_{c}}-\frac{1}{1+j}\right)+\frac{1+i}{1+j}-1 .
$$


The $N P V$ based on the equivalent discount rate can be obtained by Eqn (3).

The NPV of the alternatives are only comparable if they have the same life span. In the case of comparing alternatives with different life span, equivalent annual cost $(E A C)$ is often used as a decision support tool. The $E A C$ is the cost per year of owing an asset over its defined life span. The $E A C$ is calculated by multiplying the total net present value $(T N P V)$ by the annuity factor $\left(A_{t, r}\right)$ (Mirzadeh et al. 2013):

$$
E A C=T N P V \times A_{t, r}=T N P V \times \frac{r}{1-(1+r)^{-d}},
$$

where: $T N P V$ is the sum of all the $N P V$ s regarding construction, maintenance and rehabilitation activities during the life span and $d$ is the design life of the asphalt pavement.

The portion of energy related cost regarding each project may vary for the initial construction and future maintenance and rehabilitation. Therefore, $\alpha$ should be calculated based on the discounted energy and time related cost. However, the equivalent discount rate itself is a function of $\alpha$. In order to solve this problem a flowchart for evaluating the discount rate for asphalt pavements is presented in Figure 2. The design inputs such as the thickness of the asphalt layer for construction can be obtained from the Calibrated Mechanics based model (MC). The MC model is based on the mechanistic empirical pavement design model developed by Birgisson et al. (2006) which is calibrated by Gullberg et al. (2012) for the Swedish conditions. The initial $\alpha$ is calculated based on undiscounted energy related and time related costs. The equivalent discount rate is evaluated as a function of $\alpha$, general inflation, oil price inflation and interest rate. The new $\alpha$ is then calculated based on NPV for energy related and time related items by substituting $r$ into Eqn (9). The iteration continues as long as the difference between $\alpha_{i}+1$ and $\alpha$ is larger than $1 \%$. Once $\alpha$ satisfied the required condition, $r$ can be used as the discount rate for the asphalt pavement project. A sensitivity analysis is to be performed in order to assess the effect of the expected variation of the discount rate on the life cycle cost of the project. The sensitivity analysis should be done based on the historical values of interest rate, general inflation and oil price inflation.

\section{Results and discussion}

The variation of the discount rates for different assumed values for $\alpha$ based on the historical data regarding interest rate, inflation and crude oil price inflation for Sweden is presented in Figure 3. Expected range of change regarding the equivalent discount rates, has been higher than

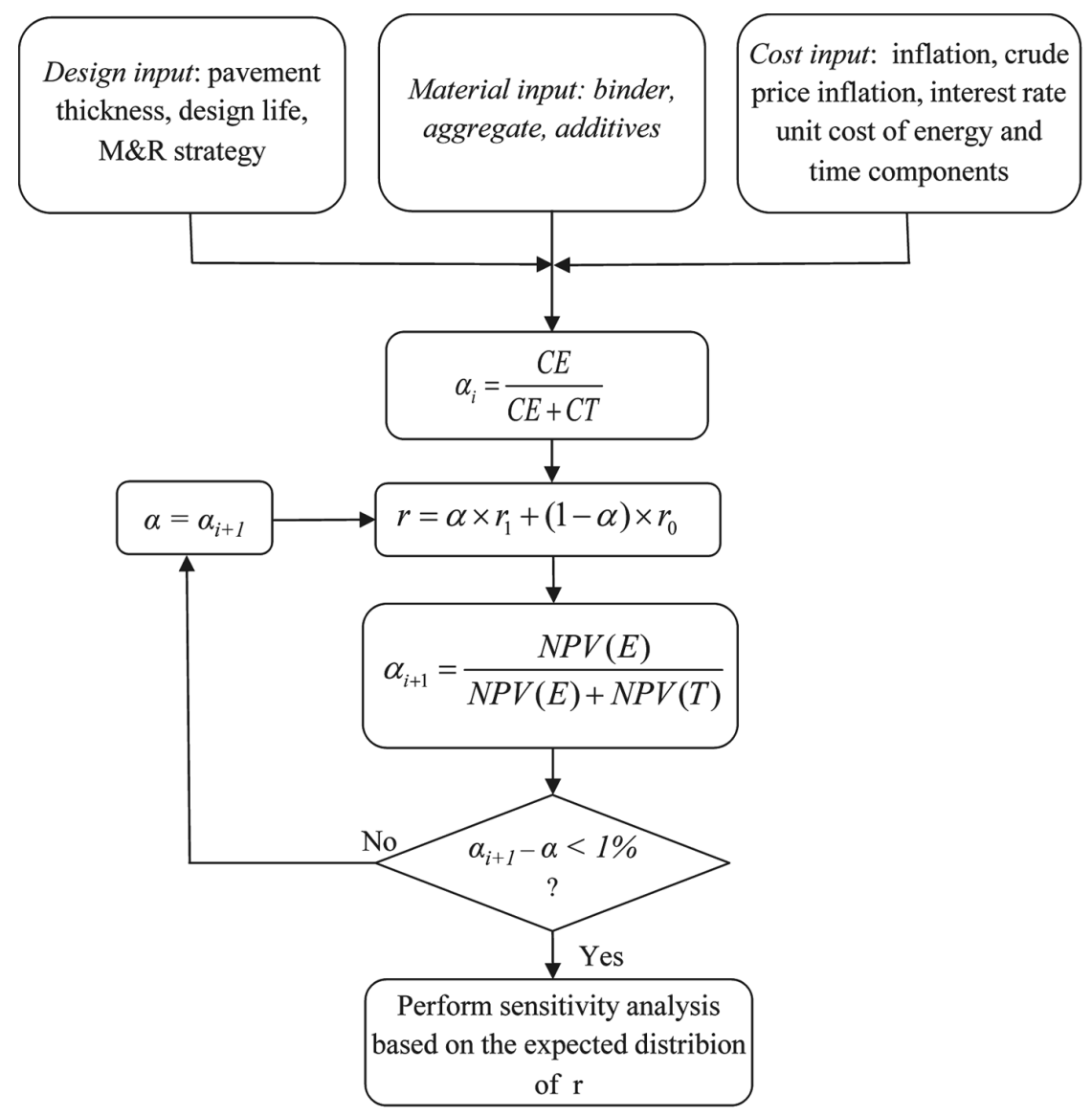

Fig. 2. The flowchart to calculate the equivalent discount rate 
the traditional discount rate. Depending on the portion of energy related items, volatility of the discount rate has excessively increased. It was observed that during 19811994 the Swedish economy faced a relatively high interest rate, inflation and an overall deflation in the oil price. This situation caused the equivalent discount rates to be higher than the traditional discount rate (Fig. 4) and beta in this period was 0.2 . The beta coefficient in this period was positive which means $r_{1}$ and $r_{0}$ changed in the same direction. However, during 1970-1980 and 1999-2012 the high crude inflation caused the equivalent discount rate to be negative and beta coefficients were -2.3 and -3.7 . The negative beta coefficients indicate that $r_{1}$ was moving in the opposite direction of $r_{0}$. The discount rate in these periods implied a rapid increase in the cost of asphalt pavement construction and rehabilitation which did not correspond to the general inflation.

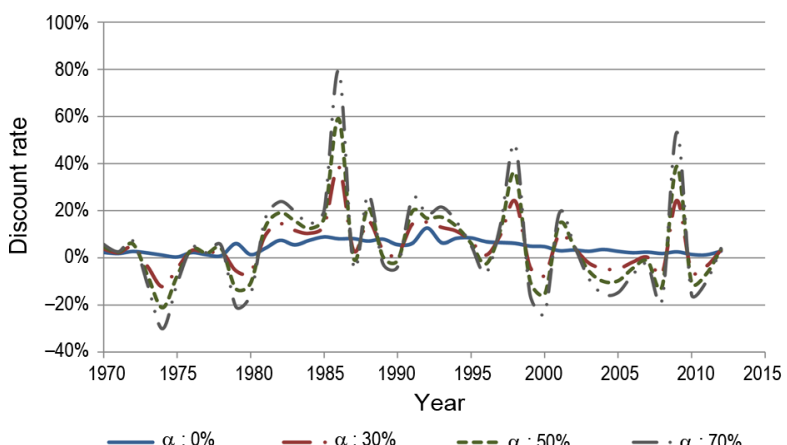

Fig. 3. The average equivalent discount rates based on the historical data for Sweden

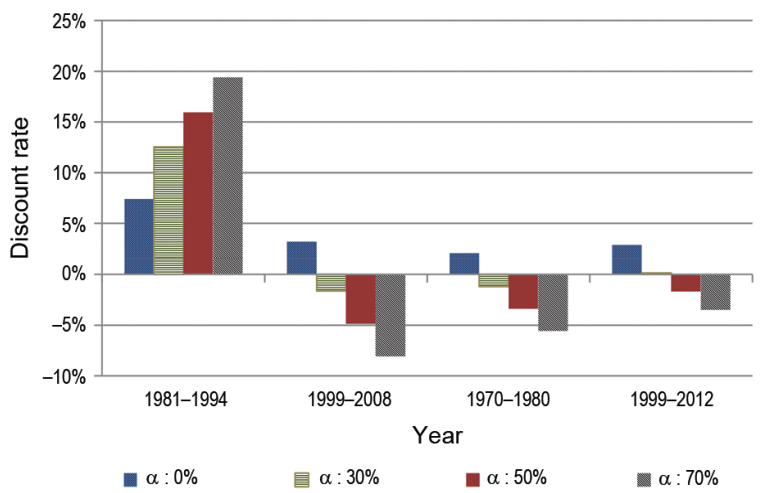

Fig. 4. The average equivalent discount rates in different time periods

The empirical cumulative distribution function $(C D F)$ of discount rates regarding energy related items $\left(r_{1}\right)$ and time related items $\left(r_{0}\right)$ during 1970-2012 in Sweden was plotted against the normal $C D F$ in order to test if they follow a normal distribution (Fig. 5). The midpoint probability plotting positions was used where the $i^{\text {th }}$ sorted values were plotted against the midpoint in the jump of the empirical cumulative distribution function $(C D F)$ on the $y$ axis. It was observed that the historical values regarding the both discount rates have followed normal distributions.

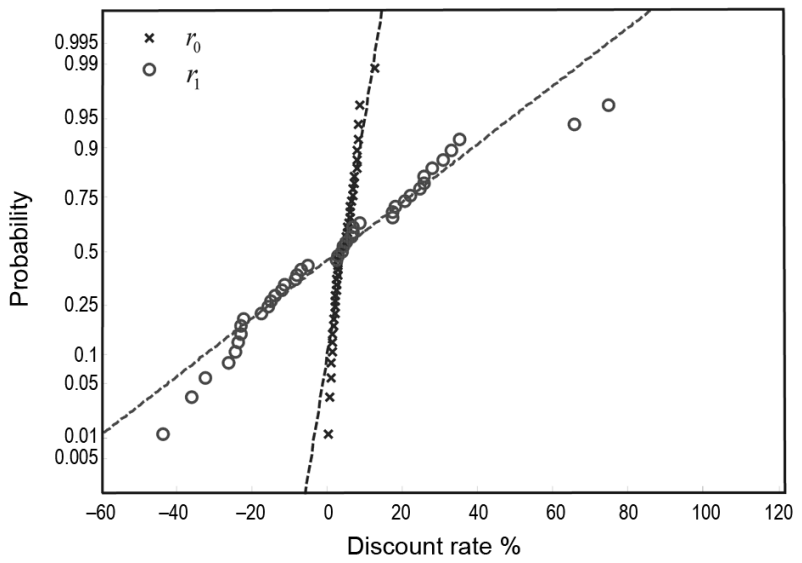

Fig. 5. Normal probability distribution plot test for discount rates regarding energy related items $\left(r_{1}\right)$ and time related items $\left(r_{0}\right)$ for Sweden during 1970-2012

The NPV for the future cost items is the multiplication of their current cost by the discount factor. The discount factor is a function of the discount rate and the year of the analysis (Eqn (11)). In sensitivity analysis regarding the current LCC studies, the discount rate usually is assumed to be positive (e.g. Ferreira, Santos 2013; Christensen 2009; Vacheyroux, Corotis 2013; Zhou et al. 2010; Churchill, Panesar 2013). However, if the inflation is higher than the interest rate from the Eqn (4) the discount rate should be negative. This behavior was observed for the equivalent discount rate in certain time periods such as 1970-1980 and 1999-2012 in Sweden (Fig. 4). The high amount of oil price inflation caused a negative equivalent discount rate in these periods. The effect of the discount rate on the discount factor is presented in Figure 6.

A positive discount rate causes the discounted value for the future costs to be lower. However, a negative discount rate makes the value of the discounted costs to be higher. This causes different interpretations of a LCC study. Having a positive value for the discount rate may imply that it is worth to invest less for the initial con-

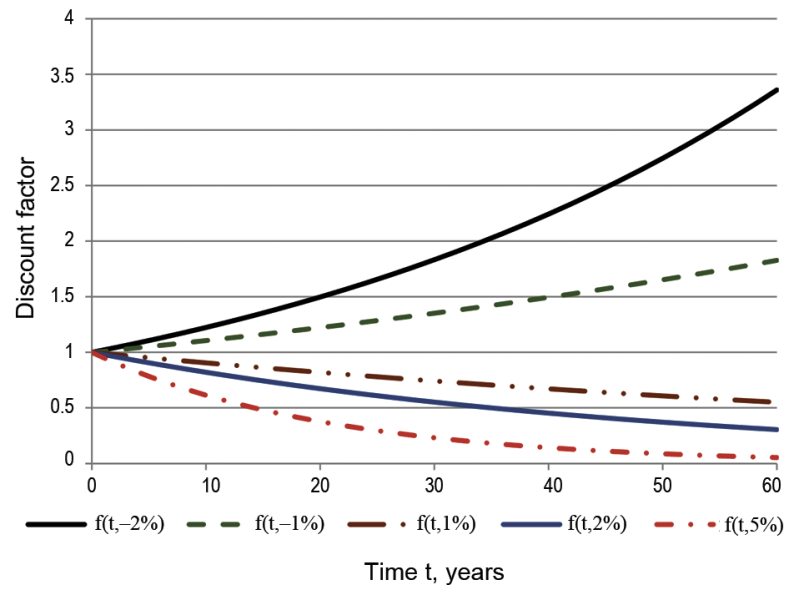

Fig. 6. Discount factor as a function of time and discount rate 


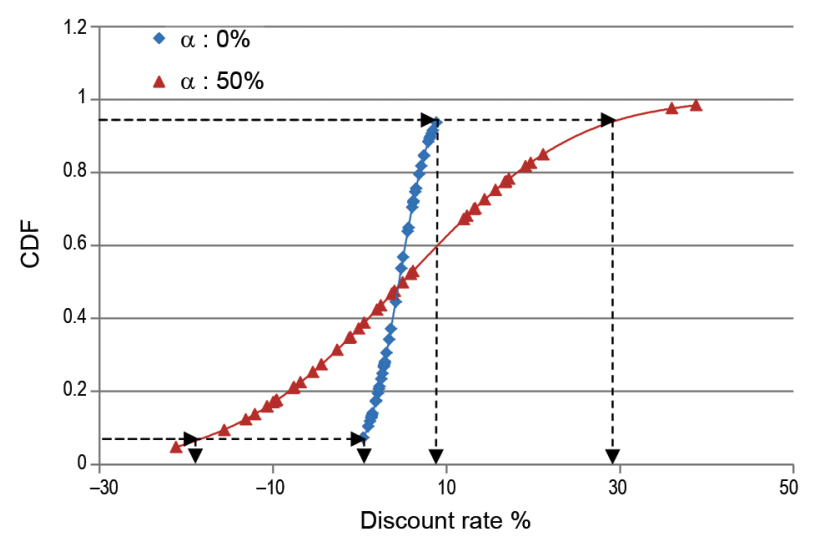

Fig. 7. Normal cumulative distributions for discount rates regarding energy related items $\left(r_{1}\right)$ and time related items $\left(r_{0}\right)$ for Sweden during 1970-2012

struction and have a higher level of maintenance and rehabilitation in the future. However, a negative discount rate supports the argument to invest more in the initial construction to lower the amount of the future costs. The cumulative probability distribution function for discount rates with $\alpha$ equal to 0 and $50 \%$ based on a Swedish data regarding 1970-2012 is plotted in Figure 7. It was observed that the common range, that is widely used in sensitivity analysis regarding discount rate for infrastructure projects (i.e. $0-8 \%$ ), is relevant for traditional discount rate $(\alpha=0)$. However, the same probability requires a range between -20 and $30 \%$ for $\alpha$ equal to $50 \%$.

The normal probability Distribution Function (PDF) for discount rates with different portion of energy related items during 1970-2012 in Sweden is depicted in Figure 8 . The probability distribution regarding $r_{1}$ with a standard deviation equal to 0.3 was shown to be a wide distribution compare to $r_{0}$ with a standard deviation equal to 0.03 . The standard deviation for the equivalent discount rate, which is a combination of energy and time related discount rates, has changed depending on its $\alpha$.

Furthermore, the shape of the probability distribution for the equivalent discount rate has been more similar to re for a higher $\alpha$ and more similar to $\mathrm{r}$ for a lower $\alpha$. This volatility has imposed a high level of financial risk to the highway projects. This financial risk is primarily

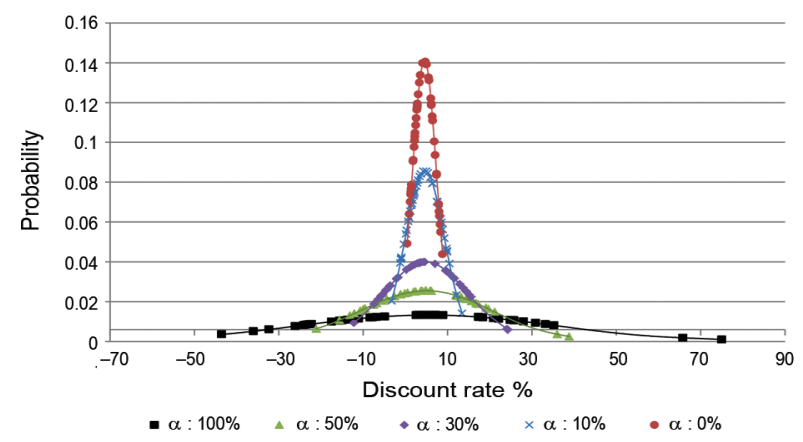

Fig. 8. Normal distributions for discount rates with different portions of energy related items during 1970-2012 subjected to the longer projects. On the other hand, it also exists during the contract time for construction contracts. The length of the contract highly affects this risk. The longer the contract the more significant the risk becomes. If the contract duration is short the high volatility should not affect the prices as the contractor has the material/fuel available before the beginning of the contract. However, the impact of volatility can be significant even for modest volatility measures for long duration contracts. The sharp increase in the level of material and fuel prices has been experienced during the last years. Consequently, a large number of contractors in the USA were affected by escalating material prices (bitumen, fuel) (Gallagher, Riggs 2006). According to the results of a survey conducted by AASHTO in 2008 (AASHTO 2009), 40 states used fuel price adjustment clauses, and 42 states used bitumen price adjustment clauses.

However, even when transportation agencies use price adjustments, the trigger levels are only arbitrarily defined and are not considered from the risk analysis perspective. For example, the Washington state department of transportation (DOT) applied the trigger value of 10\% for fuel and bitumen cost adjustments (AASHTO 2009). By considering the high level of risks (Fig. 8) the amount of the adjustments might not be sufficient.

To hedge against this risk, especially for contracts without price adjustment clauses, contractors usually have incorporated a premium in the bid price (Damnjanovic, Zhou 2009). Contractors can allocate this risk in four following ways: (1) adding the risk to the price of individual items in the contract, (2) adding the risk to the overall estimated price of the project, (3) dividing the risk and spreading it on some particular items in a bid and (4) spreading the risk on a portfolio of projects. Contractors in longer contracts are more concerned about the future prices. Therefore, they usually get engaged in hedging against commodity (material/fuel) risk with suppliers. The contractor risk premium, especially for smaller contractors, might be larger than the suppliers' premium. In this case the transportation agencies could consider including the price adjustment clauses to cover the risk of the future price increases. This can be done by hedging with purchasing options for the future consumption of the fuel and material at the predetermined fixed prices. Furthermore, this will encourage more contractors to take part in the bidding and consequently could result in overall lower bidding prices.

The equivalent discount rate reflected the risk of the change of prices and volatility regarding the crude oil. This information can be used by the road authorities in the context of managing risks on an individual project level as well as the network level. At the project level, results provide a basis for making decisions to either retain or transfer the commodity (material/fuel) price risk. For example having high values regarding $\alpha$ and the expected change in the oil price the road agency should consider price adjustment clauses. On the network level, 
the results provide a measure for minimizing portfolio risks by diversifying risk retention and transfer policies. For example, exposing only a portion of projects to risk by implementing price adjustment clauses, the portfolio risk can be minimized. For instance, an increase in the energy related prices causes only a part of the projects to be subjected to losses that are compensated by gains on the rest of the portfolio.

\section{Summary and conclusions}

This paper presented a discount rate for asphalt pavement projects as a function of interest rate, general inflation and oil price inflation which can be defined for each project based on the portion of the energy related items during the defined life time. This so called "equivalent discount rate $(r)$ " reflected the impact of energy price fluctuation on the costs and the associated financial risks related to asphalt pavement works. A flowchart was suggested for calculating $\mathrm{r}$ for asphalt pavement projects. The equivalent discount rate was studied by analyzing the historical values regarding the interest rate, general inflation and oil price inflation in Sweden during 1970-2012. The range of $\alpha$ was assumed to be between $50-70 \%$. In periods between 1970-1980 and 1999-2012 the average value for $r$ has been -4 and $-3 \%$, respectively. The beta coefficients in these periods have been -2.3 and -3.6 . The negative beta was related to high oil price inflation which changed the behavior of the equivalent discount rate. The standard deviation of the equivalent discount rate was 0.15 and 0.20 for $\alpha$ equal to 50 and $70 \%$, respectively. This was much higher than the standard deviation for the traditional discount rate in the same period. The high volatility for the $r$ was mainly caused by the high volatility in the oil price.

The following conclusions are drawn from this study:

- By evaluating the historical values regarding inflation, oil price inflation and interest rate, during specific time periods, the $r$ was shown to be much lower than the traditional discount rate $(\alpha=0)$. Therefore, applying an average traditional discount rate may lead to an under-estimation of the project costs.

- The lower discount rate, specially the negative discount rate in the recent years, implies that the future costs can be more expensive than projected due to discounting. This highlights the importance of lowering the amount of required maintenance and rehabilitation by increasing the initial construction quality.

- It was observed that the common range (i.e. $0-8 \%$ ) for discount rate sensitivity analysis regarding infrastructure projects is not suitable for highway projects. By assuming $50 \%$ of the costs related to the energy related items, the discount rate sensitivity analysis should cover a range between $-20 \%$ and $+30 \%$.

- Both the equivalent discount rate and its volatility are dependent on the amount of contribution of the energy related costs. Therefore, the discount rate should be defined based on $\alpha$ for each highway project.
- The high amount of volatility in the oil price imposed increased financial risk to the highway projects. This financial risk may highly affect the fixed-price unitbased contracts with longer time period which the owner transferred the risk to the contractor.

- By incorporating the financial risks imposed by the oil price, this paper helps the contractors and road authorities with a more transparent estimation of the total LCC cost and the associated risks related to asphalt pavement projects.

\section{Acknowledgements}

The authors would like to thank Mr. Måns Collin for his help in development of this work.

\section{References}

AASHTO. 2009. Survey on the use of price adjustment clauses. AASHTO Subcommittee on Construction [online], [cited 12 December 2013]. Available from Internet: http://fhwicsint01.fhwa.dot.gov/programadmin/contracts/aashto.cfm

Azar, S. A. 2007. Measuring the US social discount rate, Applied Financial Economics Letters 3(1): 63-66. http://dx.doi.org/10.1080/17446540600771068

Baalousha, Y.; Celik, T. 2011. An integrated web-based data warehouse and artificial neural networks system for unit price analysis with inflation adjustment, Journal of Civil Engineering and Management 17(2): 157-167. http://dx.doi.org/10.3846/13923730.2011.576806

Baker, R.; Fox, R. 2003. Capital investment appraisal: a new risk premium model, International Transactions in Operational Research 10: 115-126. http://dx.doi.org/10.1111/1475-3995.00398

Baloi, D.; Price, A. D. 2003. Modelling global risk factors affecting construction cost performance, International Journal of Project Management 21(4): 261-269. http://dx.doi.org/10.1016/S0263-7863(02)00017-0

Birgisson, B.; Wang, J.; Roque, R. 2006. Implementation of the Florida cracking model into the mechanistic-empirical pavement design: monograph. Transportation Research Board, USA. 103 p.

Brandao, L. E. T.; Saraiva, E. 2008. The option value of government guarantees in infrastructure projects, Construction Management and Economics 26(11): 1171-1180. http://dx.doi.org/10.1080/01446190802428051

Campbell, J. Y. 1993. Intertemporal asset pricing without consumption data, American Economic Review 83(3): 487-512.

Chiara, N.; Garvin, M.; Vecer, J. 2007. Valuing simple multipleexercise real options in infrastructure projects, Journal of Infrastructure Systems 13(2): 97-104.

http://dx.doi.org/10.1061/(ASCE)1076-0342(2007)13:2(97)

Christensen, P. 2009. Life-cycle cost-benefit (LCCB) analysis of bridges from a user and social point of view, Structure and Infrastructure Engineering 5(1): 49-57. http://dx.doi.org/10.1080/15732470701322818

Churchill, C.; Panesar, D. 2013. Life-cycle cost analysis of highway noise barriers designed with photocatalytic cement, Structure and Infrastructure Engineering 9(10): 983-998. http://dx.doi.org/10.1080/15732479.2011.653574

Cui, Q.; Bayraktar, M.; Hastak, M.; Minkarah, I. 2004. Use of warranties on highway projects: a real option perspective, Journal of Management in Engineering 20(3): 118-125.

http://dx.doi.org/10.1061/(ASCE)0742-597X(2004)20:3(118)

Damnjanovic, I.; Zhou, X. 2009. Impact of crude oil market behavior on unit bid prices: the evidence from the highway construction sector, Construction Management and 
Economics 27(9): 881-890.

http://dx.doi.org/10.1080/01446190903171204

Elton, E. J.; Gruber, M. J.; Brown, S. J.; Goetzmann, W. N. 2007. Modern portfolio theory and investment analysis. $7^{\text {th }}$ ed. New York: John Wiley \& Sons. 752 p.

Evans, D. J.; Sezer, H. 2005. Social discount rates for member countries of the European Union, Journal of Economic Studies 32(1): 47-59. http://dx.doi.org/10.1108/01443580510574832

Fama, E. F.; French, K. R. 2004. The capital asset pricing model: Theory and evidence, Journal of Economic Perspectives 18(3): 25-46. http://dx.doi.org/10.1257/0895330042162430

Federal Highway Administration (FHWA). 2002. Life-cycle cost analysis primer. Washington, DC: US Department of Transportation. $26 \mathrm{p}$.

Ferreira, A.; Santos, J. 2013. Life-cycle cost analysis system for pavement management at project level: sensitivity analysis to the discount rate, International Journal of Pavement Engineering 14(7): 655-673. http://dx.doi.org/10.1080/10298436.2012.719618

Gallagher, J.; Riggs, F. 2006. Material price escalation: allocating the risks. Construction Briefings, Thomson/West, Eagan. 28 p.

Garvin, M. J.; Cheah, C. Y. J. 2004. Valuation technics for infrastructure investment decisions, Construction Management and Economics 22(4): 373-383. http://dx.doi.org/10.1080/01446190310001649010

Gullberg, D.; Birgisson, B.; Jelagin, D. 2012. Evaluation of a novel calibrated-mechanistic model to design against fracture under Swedish condition, International Journal on Road Material and Pavement Design 13(1): 49-66. http://dx.doi.org/10.1080/14680629.2011.651838

Hastak, M.; Shaked, A. 2000. ICRAM-1: Model for international construction risk assessment, Journal of Management in Engineering 16(1): 59-69.

http://dx.doi.org/10.1061/(ASCE)0742-597X(2000)16:1(59)

Hegazy, T.; Ayed, A. 1998. Neural network model for parametric cost estimation of highway projects, Journal of Construction Engineering and Management 124(3): 210-218.

http://dx.doi.org/10.1061/(ASCE)0733-9364(1998)124:3(210)

Jaafari, A. 2001. Management of risks, uncertainties and opportunities on projects: time for a fundamental shift, International Journal of Project Management 19(2): 89-101. http://dx.doi.org/10.1016/S0263-7863(99)00047-2

Lally, M. 2008. Measuring the US social discount rate: reply to Azar, Applied Financial Economics Letters 4(4): 283-285. http://dx.doi.org/10.1080/17446540701720543

Lee, H.; Lee, S.; Lee, J.; Chon, K. 2009. The revenue-beta model for private participation in infrastructure, Journal of the Eastern Asia Society for Transportation Studies, Vol. 8. 13 p.

Markowitz, H. 1952. Portfolio selection, Journal of Finance 7(1): 77-99.

Melicher, R. W.; Norton, E. A. 2010. Introduction to finance: Markets, investments, and financial management. $14^{\text {th }}$ ed. Danvers: John Wiley \& Sons. 624 p.

Mirzadeh, I.; Butt, A.; Toller, S.; Birgisson, B. 2013. Life cycle cost analysis based on the fundamental cost contributors for asphalt pavements, Structure and Infrastructure Engineering. 11 p. http://dx.doi.org/10.1080/15732479.2013.837494

Pandit, D.; Anderson, S.; Damnjanovic, I.; Nejat, A. 2009. Assessment of strategies and methods to reduce construction costs while maintaining quality. Presentation at The $1^{s t}$ International Conference on Transportation Construction Management, 11 February 2009, Orlando, FL.

Percoco, M. 2008. A social discount rate for Italy, Applied Economics Letters 15(1): 73-77. http://dx.doi.org/10.1080/13504850600706537

Sharpe, W. 1964. Capital asset prices: a theory of market equilibrium under conditions of risk, The Journal of Finance 3(8): 425-442.

Sodikov, J. 2005. Cost estimation of highway projects in developing countries: artificial neural network approach, Journal of the Eastern Asia Society for Transportation Studies 6: 1036-1047.

Sonmez, R.; Ontepeli, B. 2009. Predesign cost estimation of urban railway projects with parametric modeling, Journal of Civil Engineering and Management 15(4): 405-409. http://dx.doi.org/10.3846/1392-3730.2009.15.405-409

Strong, R. A. 2008. Portfolio construction, management, and protection [With Stock-Trak]. London: Cengage Learning. 688 p.

Vacheyroux, G.; Corotis, R. 2013. Strategies of investment in the management of urban bridges: a life-cycle approach illustrated for Paris, Structure and Infrastructure Engineering 9(11): 1080-1093. http://dx.doi.org/10.1080/15732479.2012.665464

Vassallo, J. 2006. Traffic risk mitigation in highway concession projects, Journal of Transport Economics and Policy 40(3): 359-381.

Wilmot, C. G.; Cheng, G. 2003. Estimating future highway construction costs, Journal of Construction Engineering and Management 129(3): 272-279.

http://dx.doi.org/10.1061/(ASCE)0733-9364(2003)129:3(272)

Wilmot, C. G.; Mei, B. 2005. Neural network modeling of highway construction costs, Journal of Construction Engineering and Management 131(7): 765-771.

http://dx.doi.org/10.1061/(ASCE)0733-9364(2005)131:7(765)

World Bank. 2012. World development indicators 2012. World Bank. 248 p.

Yeo, K.; Qiu, F. 2003. The value of management flexibility a real option approach to investment evaluation, International Journal of Project Management 21(4): 243-250. http://dx.doi.org/10.1016/S0263-7863(02)00025-X

Zhao, T.; Sundararajan, S.; Tseng, C. 2004. Highway development decision-making under uncertainty: a real options approach, Journal of Infrastructure Systems 10(1): 23-32.

http://dx.doi.org/10.1061/(ASCE)1076-0342(2004)10:1(23)

Zhou, X.; Damnjanovic, I. D. 2011. Optimal hedging of commodity price risks in highway contracts, Transportation Research Record: Journal of the Transportation Research Board 2228(1): 19-25. http://dx.doi.org/10.3141/2228-03

Zhou, Y.; Banerjee, S.; Shinozuka, M. 2010. Socio-economic effect of seismic retrofit of bridges for highway transportation networks: a pilot study, Structure and Infrastructure Engineering 6(1-2): 145-157. http://dx.doi.org/10.1080/15732470802663862

Iman MIRZADEH. Researcher at Swedish National Road and Transport Research Institute. His research is multidisciplinary and lies at the junction of construction engineering and sustainability, project systems modeling with an emphasis on uncertainty and risk, integration of design and construction, innovative project delivery systems (e.g. design-build, public-private partnership (PPP) and private finance initiative (PFI)).

Björn BIRGISSON. Professor, Pro Vice-Chancellor and Executive Dean at Aston University. His research interests are in the field of pavements and railway tracks focusing on performance-based design, operations and maintenance, vehicle-road interaction, innovative construction materials, and the mechanics of degradation and failure. 